\title{
The Research of the Feasibility of China to Learn from the U.S. Federal Government Performance Evaluation
}

\author{
Xiaoli Shi ${ }^{1}$ \\ ${ }^{1}$ School of Management, Shanghai University of Engineering Science, Shanghai, China \\ Correspondence: Xiaoli Shi, School of Management, Shanghai University of Engineering Science, Shanghai 201620, \\ China. Tel: 86-158-2180-9467. E-mail:sues_sxl@163.com
}

Received: April 21, 2014 Accepted: May 4, 2014 Online Published: June 4, 2014

doi:10.5430/sass.v1n2p77 URL: http://dx.doi.org/10.5430/sass.v1n2p77

\begin{abstract}
Government performance evaluation is a rather effective tool of government administrative reform, government management innovation and government reengineering activities. It will be a comprehensive supervision of the operation process and result of government power and make it possible to establish a clean, efficient and responsible government. Currently, China's performance evaluation of all levels of government in both theory and practice has made remarkable achievements, however, China's government performance evaluation also encountered many problems due to the late start and the complexity of performance evaluation. Throughout the world, the U.S. government performance evaluation has the most typical representative, and it is of great significance for China to systematically study and draw the beneficial experience from the U.S. government performance evaluation.
\end{abstract}

Keywords: government performance evaluation; the feasibility; path selection

\section{The Meaning and Function of Government Performance Evaluation}

\subsection{Government Performance Evaluation and its Related Concepts}

We must accurately understand the connotation of performance, performance evaluation and government performance before scientifically defying the essential connotation of the government performance evaluation. "The performance" ,the achievement and success, is refers to the harvesting and effect of work and study, including subjective evaluation focused on results and objective evaluation focused on effect. Performance evaluation is a process to identify, observing, measuring and evaluating performance. The concept of performance can be applied to different subjects and can comment to the appropriate subject. However, for the particularity of government targets and properties, the concept of government performance has become more difficult to grasp. Scholars to the definition of government performance is always relatively one-sided, ether ignore the process of the government to provide public goods or services, or ignore the result of the government to provide public goods or services.Here, government performance can be defined as: under the condition of given resources, to achieve goals, the government implement process and results of various kinds of activity or project, which is shown by the efficiency and effectiveness of the government to provide public goods or services.

Based on the related concepts of government performance evaluation, we can define the meaning of government performance evaluation: it's a comprehensive evaluation of process and the result of the government's various activities or project under the condition of given resources and goals. It includes the political performance, economic performance, cultural performance, social performance, which involves every level and field of governmental administration.

\subsection{The Analysis of the Function of the Government Performance Evaluation}

Government performance evaluation is a very effective tool of modern government management, and it has very important significance to the development of the government, embodied in the following aspects.

\subsubsection{The Transformation of Government Concept}

Since the 1990s, the idea of the U.S. federal government performance evaluation has experienced from efficiency oriented evaluation to results oriented evaluation, encouraging all federal agencies to be responsible for the results to 
establish responsible government.Government performance evaluation is conducive to the government to set up the correct administrative concept, such as the service administration idea, the concept of customer first, the idea of responsible government, and the concept attaches great importance to the output and results, etc.

\subsubsection{Improve the Government Performance}

Because the power of the government comes from the people, the exercise of public power, improve public services and the implementation of public interest is the government's legitimacy foundation to survive. Government performance evaluation can judge whether the government provide high-quality public products and public services at a reasonable cost, and provide the evaluation information of whether the government needs to improve. In the internal control and external supervision, the government performance will surely be improved.

\subsubsection{Improve the Government's Credibility}

Government performance evaluation is government's a good chance to show the work to the public, and its process has the characteristics of fair, transparent, comprehensive and scientific. These undoubtedly helped the people understand, supervision, and participation in government work, and it will be helpful to form the benign interaction between the government and citizen, and It is also an important way to make the government transfer from" black-box operation"to" sunshine administration"

\subsubsection{Perfecting the Budget Allocation}

Government performance evaluation can provide the cost information and results of public products and service information, provide objective basis for decision makers to accurately predict the future investment, which is helpful to improve the budgetary decision-making and resource allocation. Government performance evaluation is beneficial to apply performance information to the budget process, and the government will allocate budget according to the department or project performance, which makes the performance evaluation and budget closely. Managers can also find the problems in government management according to the evaluation information, timely adjustment of the use of budgets, to use the limited financial resources in the most needed areas.

\section{The Main Achievements of the United States Federal Government Performance Evaluation}

Since Institute of New York City had the first attempt in 1905, the U.S. government performance evaluation has made a series of achievements, which has accumulated valuable experience for the exploring government.Its achievements mainly has the following several aspects.

\subsection{The Sublimation of the Performance Evaluation Value Orientation}

The U.S. federal government performance evaluation values in history is mainly divided into two categories: the one is the efficiency as the center, the other the result responsibility center. Before the 1970s, the core value orientation of government performance evaluation is leaded by "efficiency center doctrine" based on the political and administrative dichotomy theory, bureaucracy theory and scientific management theory. The performance evaluation which centered on the efficiency focused too much on the government's input, process and "off-the-shelf" output, ignored the effect of government to provide public products and service,such as quality, equity, and customer satisfaction, against the government's "public" and "service" connotation. These drawbacks inevitably impetus to the sublimation of the value concept of government performance evaluation, and go to the next stage, namely the results management. The results management not only pays attention to the amount of performance, efficiency, but also focuses on qualitative aspects of government performance, the results and effects.

\subsection{Institutionalization of Government Performance Evaluation}

All contemporary government performance evaluation theory and practical experience shows that the improvement of the law system of performance evaluation is the important prerequisite and guarantee for the success of the government performance evaluation. The government performance and results act (1993) is the first formol law in the history of the federal government performance evaluation, and it has the milestone significance. It established the institutional framework in the form of law for the federal government focused on results performance evaluation, and then it will provide the possibility of continuous use for federal agencies and congress. The bill for federal agencies must be according to the department's mission to formulate long-term strategic planning, annual performance plan, and annual performance report.

At the same time, a series of laws and regulations matching to the government performance and results act also made an important contribution for institutional construction of the government performance evaluation, and created a 
good legal environment for the smooth implementation of the government performance.

In addition, the institutionalization of the federal government performance evaluation has embodied in the establishment of the special performance management and supervision institution. These institutions had an important effect on the federal government performance evaluation of institutional construction. For example, the Office of Management and Budget (OMB) is solely responsible for review of each department strategic planning, performance planning and budgeting, and with the President's budget to congress. It is solely responsible for the project and across departments performance evaluation, and The evaluation results should be a summary form to report to the President, congress and the public by both the program assessing rating tool and three color grade card.

\subsection{The Scientific Design of Performance Evaluation Index System}

The U.S. federal government performance evaluation had designed and used the different index system according to different evaluation level, and the legal system also ensured the consistency and comparability of performance indicators. The index system by different evaluation level, as shown in figure 1.

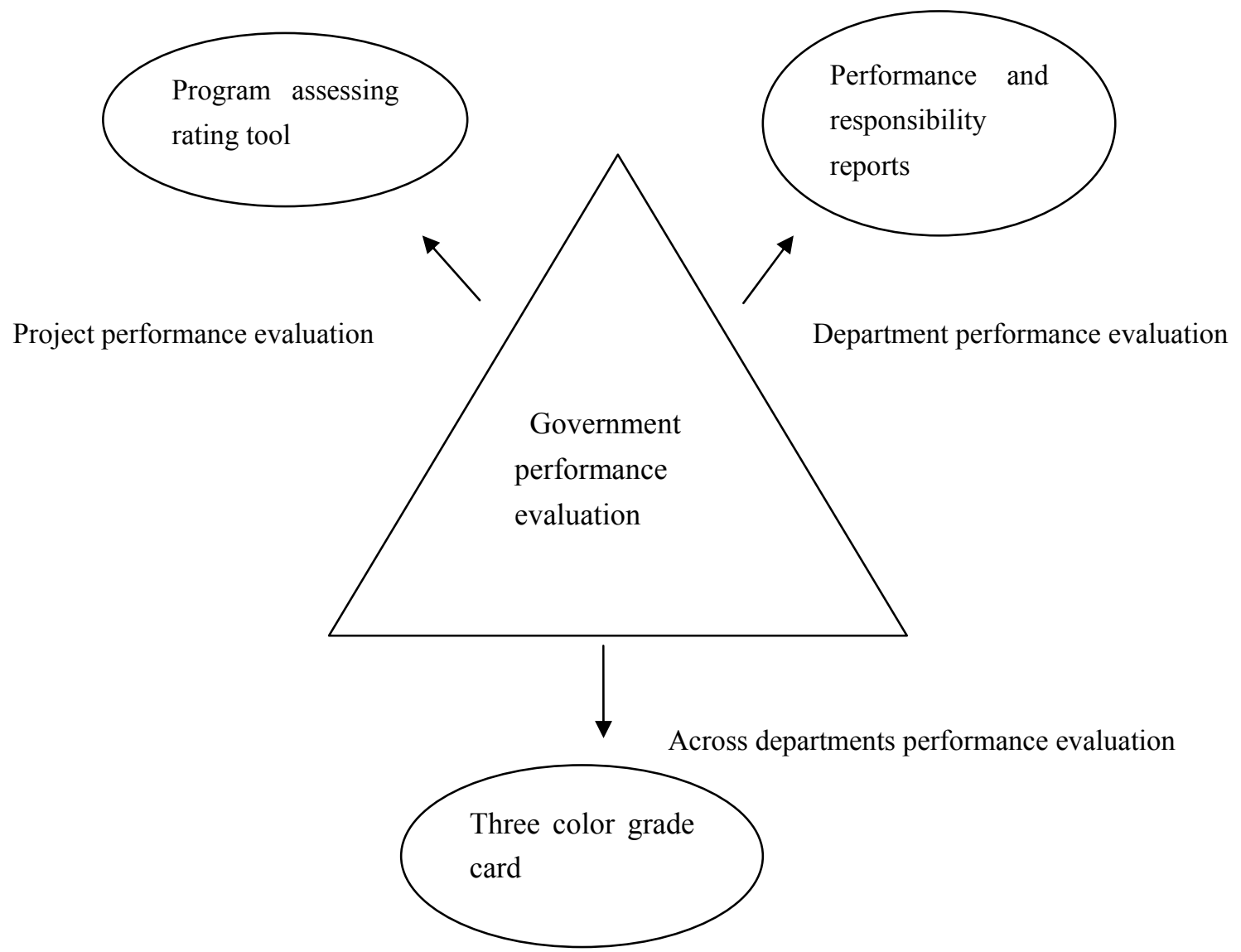

Figure 1. The index system by different evaluation level

Diagram, on the project performance evaluation level, the Office of Management and Budget (OMB) the Federal program divide the federal program into seven types: (a) Direct Federal designed; (b) Competitive Grant designed; (c)Block/Formula Grant Program; (d)Regulatory -based designed; (e) Capital Assets and Service Acquisition designed; (f) Credit Program; (g) Research and Development designed. The Office of Management and Budget (OMB) will use Program assessing rating tool (PART) make a Comparative evaluation to these federal programs, and then give the corresponding grade according to synthetically score of each project. On the department performance evaluation level, the federal government departments must set the department long-term strategic planning, annual performance plan, and report on performance and responsibility. On this basis, each department must develop a specific, distinctive, quantifiable performance index system according to the characteristics of the department and the public service. The federal ministry of Labor and social security, for example, the department performance 
evaluation in financial year 2004, USES a total of 43 performance indicators, including 9 output indicators, 34 result index. On the across departments performance evaluation level, According to the President's management agenda in the five reform initiatives, the President management committee and the Office of Management and Budget (OMB) established together the three color grade evaluation criteria and index system.It makes the red, yellow, and green three kinds of performance standards, in which each type of performance standards are composed of several different performance indicators.

\subsection{Performance Budgeting Model}

Performance budgeting, the budget system, is based on the performance. it abandoned the past bad budget mode based on last financial year's budget spending, which makes the performance evaluation information and budget more closely. The government performance and results act provides legal protection for the reform of performance budgeting, and the act requires each department put the project objectives and project performance into the process of budgeting, avoiding bad behavior only paying attention to input and process. After the bush administration took office, more emphasis on the combination of performance and budget, "in order to achieve greater performance, administrative plan must be truly combine performance evaluation and budget decisions. The budgeting based on performance will commence from fiscal year 2003." Moreover, in fiscal year 2005 of the president's budget, data prove that the project level assessment and the project budget fund are more closely than previous fiscal year.

\subsection{Democratization and Openness of Performance Evaluation}

Democratization of contemporary American federal government performance evaluation mainly embodied in the diversification of the assessment participants: (a) the federal departments; (b) The Office of Management and Budget (OMB); (c) Government Accountability Office (GAO); (d) the folk appraisal institutions. Openness of performance evaluation mainly embodied in the open and transparent information of performance evaluation process and results. In contemporary American federal government, whether the project performance evaluation, or the department and across department performance evaluation, the evaluation results must be public and shared through the performance report, government websites, and other ways, and accept the supervision of the society from all walks of life.

\section{The Status of the Chinese Government Performance Evaluation and Its Existing Problems}

The research of government performance evaluation theory in China began in the mid 1990s, because the government institutional reform in China is still in the period of transition, at the exploration stage of government performance evaluation,no matter in theory or in practice is not mature.Compared with the practice of developed countries, China's government performance evaluation has the characteristics of "spontaneous", "blindness", "random" and "closed mystique".Relative to the U.S. federal government performance evaluation, Chinese government performance evaluation system still exist some shortcomings, mainly manifested in the following aspects.

3.1 Lack of Special Laws and Regulations, no Unified Institutional Framework, Obvious Regional Differences and the Lack of Stability

Performance of legislation is an important guarantee of success of the government performance evaluation.there is no perfect legal system, there would be no stability. If there is no operational policy guidance, performance evaluation of local government will definitely is uneven.From a practical perspective, although our country have the Constitution, Audit Law, Administrative Supervision Law, National Civil Servant Law and other relevant laws and regulations, and there are a lot of rules to performance of government departments and staff, these laws and regulations ether lack of relevant entities, or the lack of a specific program,government performance evaluation without proper specification. All in all, because our country government performance appraisal do not guaranteed by unified legal and institutional framework, the performance evaluation is more often than not just a short-term behavior, lack of lasting stability.

\subsection{Lack of Scientific Evaluation Index System, Obvious Economic Value Orientation}

In August 2004, State Personnel Board and experts of China academy of personnel science launched together a set of China's local government performance evaluation index system. The assessment, by applying the analytic hierarchy process (ahp), divided the index system into three level indicators (the function index, index and potential index), 11 secondary indicators and 33 tertiary indicators. The complexity of the index system has the very big enhancement compared with Chinese past simply with GDP as the core index system.while,on the scientific, comprehensive and practical, it whether conform to the current assessment or not, it still need to the test of practice. 


\subsection{Democratization Degree is Low; Lack of Diversified Evaluation Participants and Democratic Supervision}

Government performance evaluation in China is mainly higher levels government to lower levels government evaluation, namely internal enclosed assessment. Its impartiality, scientific and effectiveness are questioned by the public. At the same time, due to a lack of information disclosure related laws and regulations, combined with the government in a strong position,government does not take the initiative to open its performance information, the process and result of government performance evaluation has a great deal of closeness and mystery.

\section{The Feasibility Analysis of China}

The U.S. government performance evaluation is based on its unique values and political system.Regardless of the specific social attributes of government performance evaluation, it is merely the government technical tools of governing the country.so the U.S. government performance evaluation exists universality experience, can be used as the basis of other countries for reference, the Feasibility analysis is mainly from the following several aspects.

\subsection{Look from the Law of Things Development}

The development of the thing itself is a spiral development process from low level to high level. The U.S. government performance evaluation is also a preliminary exploration to further improve the long-term development process. American government performance assessment problem in the development of our country government performance evaluation can also be met.China is in the early stages of government performance evaluation, as a result, summarizing the U.S. government performance evaluation experience can let our government performance evaluation go less detours. At the same time, science has characteristics of regularity, and universality. Government performance evaluation, as a government management tool and technology, also has regularity and universality, for its reasonable system design we should be using for reference.

\subsection{From the Perspective of the Target Orientation of Government Performance Eevaluation}

Whether it is the United States representative democracy, or the Chinese people's democratic dictatorship, emphasized that the government should be responsible to the people, should be to promote the development of the public. With democratic politics becoming more mature, the growth of awareness of civil rights and the development of market economy, the government public functions rapidly increase and the government's "public" connotations are more rich. Both in the United States and China, government performance evaluation is evaluation of the government public goods or public service activities. The publicity of this evaluation provides political feasibility for China to learn from the successful experience of the U.S. federal government performance evaluation.

\subsection{From the Management Idea of "the Customer is Supreme"}

The government performance evaluation is in nature a kind of market accountability mechanisms, its essence is the consumer (or public) for the direct control of the public services and choices, and the government public sector must be responsible for consumers. For the government, the customer refers to the people influenced by public policy and public management behavior, namely users of the government public service. As companies, government as a public product and service providers, should strengthen the response to the needs of the public.

Both China and the United States is the market economic system, the competition mechanism attaches great importance to using efficiency and service to win the customer's requirements. In the highly developed market economy, the U.S. government performance evaluation attends "customer first" business philosophy, and wins a series of achievements.Similarly, the establishment and increasingly mature of China's socialist market economic system and gradual increasing of "people-based, customer first" service consciousness, all provide the feasibility for our study and draw lessons from the successful experience of the us federal government performance evaluation.

\subsection{From a Series of Achievements of the Federal Government Performance Evaluation}

The advantage of the federal performance evaluation is mostly the disadvantage of our country. The values of result responsibility center,institutional construction of performance evaluation, scientific index system, performance budgeting model,democratization and openness of performance evaluation, these achievements are in line with Chinese value concept, and conducive to the development of China's political and economic system construction. After analyzing the current situation and existing problems of Chinese government performance evaluation, we should learn from the successful experience of the United States. 


\section{Path Choice of Chinese Government Performance Evaluation}

\subsection{Speed up the Performance Legislation, and Build up the Institutionalization of Performance Evaluation}

The successful experience of the federal government performance evaluation tells us that the legislation is the premise and guarantee for successful performance evaluation.Speeding up the performance legislation, and fixing the system architecture, running mechanism and method technology of performance evaluation in the form of law, is fundamental way to successfully promote Chinese government performance evaluation. Performance legislation uniformly demands the governments at various levels to boost performance evaluation.which is advantageous to the performance evaluation in the whole advancement; Legislation is conducive to the standardization of the performance evaluation and performance continuity, avoiding the change because of the change of leadership or subjective will; Performance legislation can also provide institutional platform for comparison evaluation of department or project. However, because short time and less experience of Chinese government performance evaluation, the current conditions of performance legislation directly by the National People's Congress (NPC) is not yet mature. In this case, the State Council can formulate relevant regulations or rules of performance evaluation.when the conditions are ripe, The National People's Congress (NPC) can carry out performance legislation.

\subsection{Guided by the Scientific Outlook on Development, and Make Scientific Performance Evaluation Index System}

The federal performance evaluation index system, there are two notable characteristic, namely quantitative index significantly more than the qualitative index, the results index significantly more than the process and output indicators. In the process of participating in Chinese local government performance evaluation practice, we deeply feel that the advantages of the U.S. federal government performance evaluation index system is exactly what we lack. In a sense, the government performance evaluation was to evaluate the degree of implementation of government functions. Therefore, the government performance evaluation index system can also design on the basis of the government functions. Under the condition of socialist market economy, the Chinese government's main function is to adjust the economy, market supervision, social management and public services. On this basis, we could design four types of performance evaluation system: (a) economic development index; (b) social development indicators; (c) sustainable development indicators; (d) the administrative development indicators. These four types indicators can be designed a secondary or tertiary index according to China's national conditions.

\subsection{Promote the Reform of the Budget System}

Reforming the traditional budget system and combining the grade of the government performance assessment and budget allocations, would be an important condition for the successful performance evaluation.The federal government three levels performance assessment all closely linked to budget allocations, which provide continuous power and strong incentives for performance evaluation, and this is also the important reason for its success. While Chinese government performance progress status and budget allocations almost have no direct link, this is, of course, not conducive to promote the enthusiasm of the government or department performance evaluation. Anyway, Chinese government performance evaluation should combine performance evaluation and budget. The core of the modern government performance evaluation is to make the government administration effectively, spend the least money to do the best thing. In the annual work plan, the government departments should plan the work in detail and put forward the annual budget. And then, at the end of the fiscal year, the performance evaluation mechanism compare the final result to the budget target, if the department's budget exceed budget goal or project performance is not reach the goal, the sector's performance evaluation results will be directly affected, and may also affect next year's budget fund.

\subsection{Attach Great Importance to the Openness and Using of Performance Evaluation Results}

First of all, the evaluation result should be public. Only by making the government's work under the supervision of the public, the public interests can be guaranteed. The openness of performance evaluation results will form a kind of pressure to the government, and it is one of the effective ways to Oversee the government behavior. Second, the assessment results should be used as an important basis for the punishment and incentive to departments and civil servants. For the outstanding evaluation result shall be rewarded; For the poor evaluation results, should take disciplinary measures.

\section{Conclusions}

Through the long history, the U.S. government performance evaluation has accumulated rich experience, and 
provides important reference for Chinese government performance evaluation. This article starts from a series of achievements of the federal government performance evaluation, finding out a series of problems of China government performance evaluation, and then analyses four aspects feasibility of China to learn from the U.S. federal government performance evaluation, proves that China could learn from America's good government management tool. Finally,give Chinese government performance evaluation some suggestions. Actually,any management tools will show different advantages and disadvantages at different time in different society. In the practice of Chinese government performance evaluation,we should study systematically and draw the beneficial experience from the United States federal government performance evaluation, avoiding unnecessary error,and choosing a path with little detours.

\section{References}

Jay Fountain, \& Julia E. Melkers. (2002). Performance Measurement at the State and local level, a survey results.

$\mathrm{Lu}$ Gang. (2006). Problems of local government performance evaluation in China and its improvement countermeasures. Journal of New Oriental, 1 .

Peng Lanxiang, \& Huang Ji. (2007). China and the United States government performance audit comparison and enlightenment. Monthly Accounting, 5.

W. Gowlin. (1986). Evaluating performance in governmental organizations. The Government Accountant's Journal.

Zhang Yanhong. (2008). Government performance evaluation: review, explore, and improvement strategies. Political Science Research, 5.

Zhu Liyan, \& Zhang Qiang. (2005). The American federal government performance evaluation methods and techniques. Journal of China national school of administration, 6. 